\title{
Coping with Sexual Assault: The Roles of Account-Making and Confiding
}

\author{
John H. Harvey, ${ }^{1}$ Terri L. Orbuch, ${ }^{2}$ Kathleen D. Chwalisz, ${ }^{1}$ \\ and Gail Garwood ${ }^{1}$
}

Accepted January 24, 1991

\begin{abstract}
A study was conducted to evaluate the roles of account-making (i.e., story-like constructions involving explanations, reported memories, description, and emotional expression) and confiding in empathic others as facilitators of recovery for survivors of sexual assault. Twenty-five women and one man anonymously participated in a questionnaire study that asked them to provide accounts of instances of sexual assault, their own and others' reactions to the assault, and their perceptions of the impact of the assault on aspects of their lives. Respondents' reactions were coded and classified by independent raters. Consistent with parts of the theoretical conception, included among the findings were the following: (1) account-making was positively associated with successful coping and with helpful confidant reactions; (2) empathic confidant reactions occurring early after the assault led to more successful coping than did nonempathic reactions occurring either in the first twelve months or later after the assault; and (3) incest survivors indicated that they had more difficulty in coping and in their close relationships than did nonincest survivors. The data are discussed in terms of the value of story-construction activities and confiding as vital to the recovery process.
\end{abstract}

KEY WORDS: sexual assault; incest; account-making; confiding.

\section{INTRODUCTION}

None of us can help the things life has done to us. They're done before you realize it, and once they're done they make you do other things until at last everything

${ }^{1}$ University of Iowa, lowa City, Iowa 52242.

${ }^{2}$ University of Michigan, Ann Arbor, Michigan 48109. 
comes between you and what you'd like to be, and you have lost your true self forever. (Eugene O'Neill (1926). The Great God Brown, Random House, New York).

My father forced me to give him oral sex when I was between 11 and 14 years of age. I felt disgust, horror, and deep loathing for him as a person ... (excerpt from account of participant in present study)

I would have to write a whole book to answer this question. From the time I was 5 to 16 I was raped repeatedly by male family members, and I was beaten when I told on them. No one believed me . . (excerpt from account of participant in present study)

I was approximately 9 years of age. I'm not sure how many times the following happened. My parents sent me to see this doctor (chiropractor) for what I'm not sure. I would enter the treatment room, and he would have me take my clothes off and lie face down on the treatment table. He would then proceed to use the vibrating machine. First on my back and then between my legs and around by vagina with uncomfortable force. Then he would straddle me ... (excerpt from account of participant in present study)

As the above excerpts suggest, sexual assault represents one of the most traumatic events a person can suffer. Severe, repeated incidents of assault such as incest devastate one's sense of control over key aspects of life, make one wary of and even cynical about close relationships, and in general, as O'Neill suggests, diminish greatly one's sense of self-esteem and personal identity.

The present work was designed to assess the reactions of a sample of persons (all but one of whom were women) who were willing to report about incidents of sexual assault in their lives. We were concerned principally with their accounts of these events and their subsequent coping, including how the act of confiding about the assault may have related to adjustment. We approached this topic from a theoretical position that focuses on the social psychology of people's account-making about severe stress as a facilitator of coping and adjustment (Harvey et al., 1990). We define account-making as people's story-like constructions of events that include explanations, descriptions, predictions about relevant future events, and affective reaction. A major assumption of this theoretical position is that people tend to engage in such activity when they are troubled by imposing problems in their lives; and further, they develop subaccounts for particular events that ultimately become woven into larger profiles in the form of a master account of events in their lives. Within the context of attribution theory in social psychology, our initial work on accounts (e.g., Harvey et al., 1978) began as a follow-up to Weiss' (1975) powerful analysis of marital separation that emphasized the organizing and energizing effect of accounts in the lives of persons adjusting to the loss of a close other. Weiss viewed the development of the account as vital in the chain of events in which a person achieves closure about the loss of a relationship and 
motivation to move on in life. Our work on account-making now has been extended also to include consideration of the role of accounts in other stressful circumstances, including Vietnam combat veterans' reactions to life after the war (Harvey et al., 1989) and elderly persons' reactions to the loss of loved ones by death, divorce, and relocation (Weber et al. (1987). Available evidence suggests that well-developed accounts play a salutary role in providing perspective, the will to carry on, hope about the future, and closure regarding such stressors [see Harvey et al. (1990) for a general review].

We should note that our work on account-making both overlaps with and runs parallel to a number of lines of theory and research in the social sciences. The concept of accounts was given prominence in the work of Lyman and Scott in sociology (e.g., 1970) who were amplifying on Goffman's earlier influential work on how people present themselves in everyday conduct (e.g., Goffman, 1959). At present, there are active programs of research on how people develop accounts for social predicaments or potentially blameworthy actions (e.g., Cody and McLaughlin, 1991). Our concept of accounts is broader in scope than the concept of accounts emphasized by these scholars in that we are interested in account-making across a variety of situations, including but not restricted to those involving self-esteem protection and enhancement. Also, the accounts concept as we construe it overlaps with the idea of narratives and their roles in social behavior (e.g., Gergen and Gergen, 1988), with conceptions about the value of story-telling as a generally constructive endeavor in life (e.g., Coles, 1989), and to "folk psychology" (e.g., Bruner, 1990).

In considering how account-making enters into people's reactions to severe stressors, we have borrowed and elaborated on Horowitz's (1986) sequential stage-model of reactions to stress. In Fig. 1, we theorize that account-making is particularly apt to become most pronounced in intensity and scope in what Horowitz calls the "working through" stage of coping. We suggest that in earlier stages, such as those involving denial, only fragmentary account-making occurs and that later accountmaking is virtually complete except for long-term and periodic review and revision activity. We endorse Horowitz's proposal that failure to work through major stressors may lead to chronic problems including psychosomatic illness.

In our conception, account-making typically begins in private reflection and may progress quite far before it begins to be reported substantially in confiding activity. The extent to which an individual may confide a privately-developed account to other probably varies as a function of contextual factors, including: how close and caring the other person is to the 
account-maker; the account-maker's evaluative apprehension about the other person's reactions to the account; the other person's actual reaction to the account; and the account-maker's articulateness in the confiding activity.

In the present work, we were interested in respondents' reports of activities related to account-making about their trauma, when the traumatic activities occurred, whether or not the respondents confided in others and, if so, the others' reactions, and long-term coping strategies and perceptions of how the assault affected respondents' close relationships over time. Our ideas about the role of account-making and related confiding in coping with sexual assault are similar to those advanced by Pennebaker (1985, 1989) in his influential work showing that victims/survivors of traumatic events often have improved psychological and physical health if they have confided about their trauma. In Pennebaker's program of research, the focus is on health outcomes associated with confiding behavior, and there is less emphasis on the contents of the confiding act and the social aspects of the interaction with the confidant. The present work involves a somewhat different focus in that we emphasize the contents of the accounts and the social dynamics involved in the confiding experience (e.g., whether or not the confidant is empathic).

What does the general literature on recovery from sexual abuse tell us about the roles of confiding and/or accounts-type processes in coping? There has been little explicit commentary or research on this process [see Koss (1990) for a perceptive general analysis and review]. However, more generally, it is known that recovery for many persons is a long-term process, and that few victims seek any type of formal help (e.g., counseling) immediately after the assault (Koss, 1985). One may be especially reluctant to seek help when the assault involves incest and the consequent shame and feelings of disloyalty toward a member of one's own family. A number of specific problems have been identified for rape and incest survivors 1 year or more past the assault, including: fear, mistrust, sexual difficulties, depression, guilt, and marital and relationship problems (Becker et al., 1982; Miller et al., 1982; Quina and Carlson, 1989). As Taylor et al. (1983) suggest, this type of trauma likely challenges a person's belief in personal invulnerability and that the world is meaningful. One of the most common attributional patterns for survivors is the blaming of self, or self-directed negative attributions (Quina and Carlson, 1989), that may be fed by the reactions of others and the media in analyses of the event. Long-term successful adjustment likely involves the development of an account that provides more in-depth understanding of the event and an interpretation that takes the onus off of self as the responsible agent. 


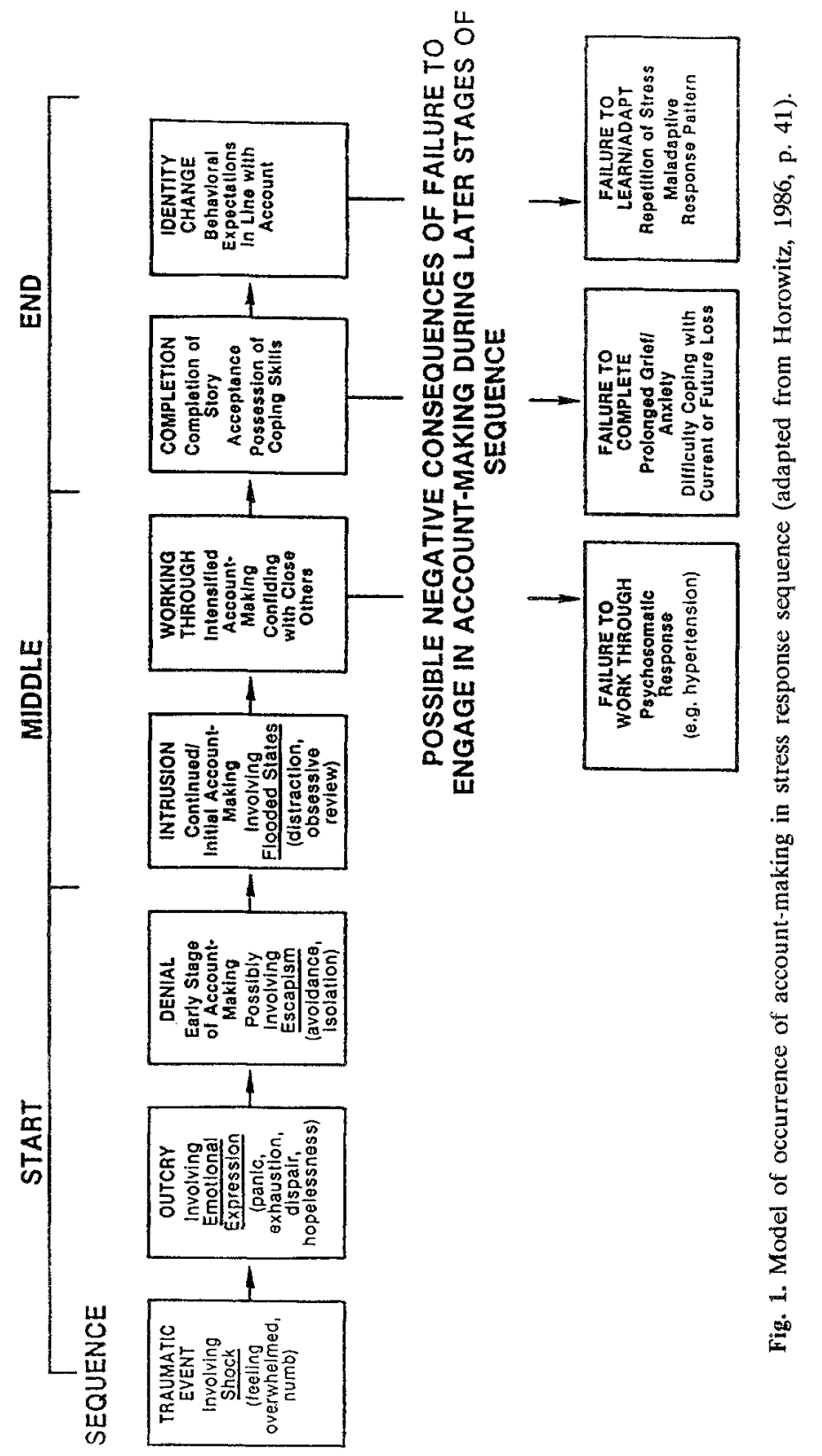


Work at comprehensive account-making, along with confiding that proves useful to the survivor, should help recast one's sense of vulnerability within a structure of meaning about the trauma, especially a structure that provides a sense of understanding of why the trauma occurred, its long-term impacts, and its possible value in the survivor's life. The more traumatic the assault (as experienced by the survivor), the greater will be the destructive effect on the survivor's identity. Thus, for major traumas, identity reconstruction may be an imposing task. Such reconstruction likely will involve building trust in significant others in whom one can confide, allaying a perception of personal culpability in the instigating event, and restoring one's sense of worth as a person. We assume that this reconstructive process will be facilitated by account-making and productive confiding in others. Productive confiding is interaction with other(s) that involves other's empathic and helpful response and in turn one's own sense of greater relief, acceptance, clarification and direction for further coping.

Silver et al. (1983) conducted a study that is highly relevant to the present work. These investigators recruited a sample of 77 adult women through advertisements in personal columns of newspapers in the area of Southern Ontario, Canada. The focus of the study was on incest involving fathers or other male guardians. Eighty percent of a group of telephone responders received and returned a 29-page questionnaire that the investigators had prepared. Overall, among the central findings of this research were that women who were able to make some sense out of their experience reported less psychological distress, better social adjustment, higher levels of self-esteem, and greater resolution of the experience. Most of the respondents reported that they continued to search for meaning, even 20 years after the incest, and that they continued to have intrusive and upsetting thoughts about the events. This evidence is directly relevant to the objectives of the present study. The more specific process of account-making clearly involves at its core a search for meaning.

A major hypothesis of the present study is that account-making about the traumatic event will be positively associated with psychological functioning at later points in time. Based on the valuable work of Silver et al. (1983) we expect that such account-making activity will be related to enhanced adjustment both for survivors of incest and of nonincestuous assault. At least a beginning of such cognitive/emotional work somewhere during the early to middle phases of the coping sequence would seem to be essential for later major adjustment steps. Although for many this beginning work may not obliterate the intrusions and ruminations about the event, it likely will provide momentum and a foundation for later accountmaking and confiding. For all persons participating in this study, the 
assault(s) had occurred at least one year prior to their participation, and the average length of time since the assault occurred was 18.5 years. Thus, for most participants, it may be assumed that in terms of time since the assault, they likely would have had enough time to be at least working on resolution of their feelings and experiences - although we hasten to acknowledge that this progression probably is quite idiosyncratic and subject to many influences in each person's life.

Another major prediction is that confiding in others relatively early in the adjustment period will be positively related to the long-term perceived success of coping, but primarily when that confiding leads to a helpful response (e.g., empathic, nonjudgmental listening, consoling, feedback about reactions, and next steps in coping) from a close other(s). If the confiding meets with a nonhelpful reaction from other(s), we anticipate that such a reaction will be associated with less successful coping. We also hypothesize that more severe, debilitating reactions will be associated with persons suffering incest versus persons suffering assault from nonrelatives.

\section{METHOD}

\section{Design and Research Participants}

Twenty-five women and one man between the ages of 20 and 44 answered an advertisement in the local newspaper inviting persons to participate in a study of nonconsensual sexual activity. Persons interested in participating were asked to contact one of the study's investigators at the university's psychology department to make arrangements to receive and to mail back the study questionnaire. In this contact confidentiality was assured; the investigators emphasized that they did not want to learn the identity of the respondents.

In addition, potential respondents were alerted to the possibility that the act of filling out the questionnaire might be emotionally difficult and that they should consider carefully whether or not they were prepared to answer such questions. Other than the opportunity to contribute to our understanding of the psychological effects of sexual assault, no money or other incentive for participation was offered. Potential respondents also were given the option to receive a reference to one of two university counseling services if in their contact they suggested that they really desired formal therapy. The set of 26 respondents derived from a total of 36 persons who made contact with the investigators (i.e., there was a $28 \%$ attrition rate). 


\section{The Questionnaire}

In constructing the questionnaire, we tried to develop items that would permit a test of the theoretical ideas but at the same time allow respondents to report freely aspects of the assault and subsequent reactions and feelings. Aside from questions about age and dates of events, all of the questionnaire items were open-ended questions. Thus, as will be elaborated in the results, responses to the key items required coding by independent raters. The questionnaire included the following principal areas of inquiry: (1) relationship of the perpetrator to the assault victim; (2) an account of the assault, including information on who perpetrated the assault and where, and with what force, and the respondent's thoughts and feelings at the time of the assault; (3) whether or not the respondent had confided in any other person about the assault, and if so, in whom they had confided and when, their relationship with the confidant, and the reactions of the confidant to their story; (4) ways they had tried to cope with the assault over time; (5) their sense of how the assault had affected them, including how it had influenced their close, personal relationships; (6) how they now feel emotionally in regard to the assault; and (7) any other types of comments or input they wished to make about the assault.

\section{RESULTS}

\section{Characteristics of Sample and Sexual Assault Event}

The 25 women respondents averaged 32.6 years of age. The 1 male respondent was 44 years of age. All respondents lived in the Midwestern part of the United States. As noted in the introduction, the average length of time since assault was 18.5 years. The range was 1 to 36 years. Analyses of variance including age of respondent and years since assault yielded no significant effects for these factors.

Categories for the perpetrator of the sexual assault for the female respondents were the following (with all being male except the one indicated): adult stranger ( 1 case), babysitter (1 case), priest ( 1 case), 2 truck drivers ( 1 case), chiropractor (1 case), adult friend of family (1 case), 16year-old neighborhood acquaintance (one case), dating partner (two cases), acquaintances living in same building/neighborhood or attending same university (five cases), brother (four cases), father (five cases), stepfather (two cases), uncle (one case), grandfather (one case), step-grandfather (one case), mother (one case). The one male respondent reported being assaulted by his mother. The number of cases for the 25 females adds up to 
more than 25 because 7 of the respondents reported separate assaults by different perpetrators. Overall, there were reports from 13 persons who had suffered incest assault and from 13 persons who had suffered assault from nonrelatives.

The questionnaire completed by the male respondent was incomplete. We did not include his data in the analyses reported below, which pertain only to the 25 female respondents. His reactions on the questionnaire were brief and indicated that the assault by his mother occurred in early childhood and that he couldn't remember the details; he noted that "It's too horrifying."

Only a few of the questionnaires filled out by female respondents were brief and sketchy. Many described events and reactions in great detail, with three involving multiple additional pages of reactions. Nine of the women explicitly mentioned formal therapy as one of the means by which they attempted to cope with the assault. The role of formal therapy in the coping process was not evaluated statistically because no explicit question about therapy was asked in the questionnaire. However, the use of formal therapy was often mentioned by these respondents, who also were judged by independent raters to reveal generally high degrees of account-making activity (see later discussion of rating procedure). Thus, there is suggestive evidence about the role of therapy in the tests of relationships between account-making and successful coping described below. In answer to a specific question about whether respondents had reported the event to authorities, only 5 out of the 26 indicated that they had; two of these respondents were reporting on assault by their brother; one was reporting on assault by her stepfather, one by an acquaintance, and finally one by a stranger who turned out to be a serial rapist when later apprehended. Regarding why the others did not report the event to authorities, the reasons given fell into the general categories of "too young and afraid," "too vulnerable," "feeling of personal fault" for the event, and confusion regarding what had happened and whether or not it was morally right.

Two independent raters coded all written questionnaire evidence pertinent to the hypotheses of the study. The two raters achieved an $83 \%$ agreement rate for the variable dimensions listed below. Over all respondents and all response dimensions there were only two major disagreements (i.e., rating discrepancies of greater than 2 points on a 10-point scale). In addition, coefficients of interjudge agreement for nominal scales (Cohen, 1960) were calculated to correct for the influence of chance agreement in the ratings. These coefficients ranged from 0.68 to 0.80 , and all were significant at the 0.01 level by $z$ score tests. 
The variable dimensions were: (1) when confiding about the event occurred, during the first 12 months (early) or after 12 months (late); (2) perceived empathic and helpful reaction of the confidant, rated along a scale of 0 to 10 with 10 representing most helpful reaction; (3) extent that the respondent had successfully coped with the event, rated along a scale of 0 to 10 with 10 representing highly successful coping; (4) extent of explicit mention of account-making activity, including formal therapy, helpful discussion of the event with other(s), diary/journal recording, periods of private reflection about the event and its implications for them rated along a scale of 0 to 10 with 10 representing a high degree of account-making activity; (5) the respondent's perception of how negative the event had been in influencing personal close relationships over time, rated along a scale of 0 to 10 with 10 representing the greatest negative impact; and (6) rated present feelings about the event, rated along a scale of 0 to 10 with 10 representing highly negative affect. (It should be noted that no question about positive impact of the event on close relationships was asked; however, the accounts and other data suggest little if any positivity of impact on relationships was accorded to the event.)

\section{Tests of Predictions}

Correlations among the coded variables revealed a degree of support for the a priori expectations. We expected that account-making would be positively related to various indices of adjustment. Consistent with this expectation, account-making was significantly negatively correlated with present negative affect $(r=-0.35, p<0.02)$ and significantly positively correlated with successful coping $(r=0.53, p<0.003)$, but was not significantly related to negative impact on close relationships $(r=-0.13)$. Also, account-making was positively related to positivity of confidant reaction $(r=0.51, p<0.003)$. Further, as expected, positivity of confidant reaction was negatively correlated with negativity of impact on close relationships $(r=-.58, p<0.001)$ and positively correlated with rated success of coping $(r=0.75, p<0.0001)$.

A number of one-way ANOVA's were conducted to test further the predictions about differences between the intrafamilial (incest) and extrafamilial (nonincest) groups. As was expected, it was found that the relative vs. nonrelative independent variable led to significant main effects on: (1) rated negative impact on close relationships (with intrafamilial cases producing greater negative impact, $F=7.57, p<0.01$, $\mathrm{df}=1 / 23$ ); (2) success in coping (with intrafamilial cases producing less rated success, $F=18.92$, $p<0.002$, df $=1 / 23$ ); (3) rated degree of present negative affect (with 
intrafamilial cases producing greater negative affect, $F=14.33, p<0.001$, df $=1 / 23$ ).

One major hypothesis of the study was that confiding that resulted in a helpful reaction would be more positively related to coping than would confiding that resulted in a nonhelpful reaction. We tested this hypothesis by categorizing women respondents into the groups of early confidepositive reaction (seven cases), early confide-negative reaction (six cases), and late confide-negative reaction (nine cases). We only had three cases of late confide-positive reaction reported; thus this group was not entered into the analysis. We should note that the role of the confidant was not systematically related to the findings. Most of the confidants were in the roles of close friends, parents and relatives, or therapists.

Three ANOVA's were conducted and revealed these findings: a main effect for the group factor for success in coping $(F=8.90, p<0.002$, $\mathrm{df}=2 / 19)$ and for present negative affect $(F=4.20, p<0.03$, df $=2 / 19)$, but no main effect for impact on close relationships. It is possible that this lack of significance for the impact on close relationships variable was due to a ceiling limitation in response rate since all respondents reported a relatively high (mean $=7.4$ ) degree of negative impact on their close relationships. $T$-tests to determine better the source of variation for these groups showed that the early confide-positive group led to significantly greater coping and less negative affect than did either the early confidenegative or the later confide-negative groups; the latter two groups did not differ from one another. Overall, then, there is some support for the idea that confiding that occurs early and meets with a helpful reaction will contribute positively to coping and lessen maintenance of negative affect regarding the assault.

Evidence regarding the foregoing idea also was provided by one-way ANOVA's for early vs. late confiding and helpful vs. nonhelpful reactions. For the early vs late tests, the ANOVA showed a significant effect on rated degree of account-making activity in coping (earlier confiding produced the greatest degree of account-making $(F=4.25, p<0.05$, df $=1 / 23)$ and a marginal main effect for the success in coping measure $(p<0.08)$, with early confiding associated with greater success than late confiding. For the helpful vs nonhelpful ANOVA's, significant main effects occurred for the success in coping $(F=11.12, p<0.05$, df $=1 / 23)$, present negative affect $(F=4.73, p<0.05, \mathrm{df}=1 / 23)$, and impact on close relationships $(F=$ $4.73, p<0.05$, df $=1 / 23$ ) measures. Examination of means showed that helpful reactions led to greater success in coping, less present negative affect, and less negative impact on close relationships than did nonhelpful reactions. These data support and reinforce the foregoing conclusion regarding the value of helpful reactions to confiding attempts and also suggest 
that early confiding assists the development of account-making and more general coping responses.

\section{Descriptive Evidence: Excerpts from Respondent's Questionnaires}

The following excerpts are presented as illustrations of both the depth of survivors' responses and of the coding scheme used for the questions of main theoretical interest in the study: (1) an example of accountmaking activity that produced a mean rating of 10.0: [after an assault at ten years-of-age by brother] ". . . stayed a virgin for many years .... went for counseling, family counseling several times ... psychotherapy \& group therapy this last year [now 34 years old] . . took emotional healing course twice lately ... letters \& phone calls to the family, parents, sisters and bothers, to my brother the abuser. I'm right now making a family tape \& a letter to my ex-husband who was emotionally and physically abusive." (2) An example of attempted confiding that was met with reactions that produced a mean rating of 0.0 (nonhelpful and nonempathic): [after 10 years of abuse between the ages of 8 and 18 by brother] "The first time I revealed the abuse was to [a state service agency] and my parents when I was twelve. [The agency] concluded it was normal sibling curiosity. My parents reacted with anger towards me, yelling about my brother's reputation if it should get around town. Their reactions left me feeling totally isolated and alone. Forcing me to be victimized for another four years ...." (3) Another example of reactions to confiding that produced a mean rating of 0.0 : [after assault by priest when respondent was small child] "I waited until I was 19 to tell my mother about the priest. She said it never happened. I waited until my middle 30's to bring it up again in a letter to my parents .... My parents never engaged me in any conversations about it until last summer [she is now 41] when my mother asked for information about the priest. My father refuses to discuss it." (4) An example of a confiding attempt that produced a mean rating of 8.5: [after rape of respondent at 19 by a dating partner, responding now at age 29]: "I shared bits and pieces with various close friends . . . but the only person I have shared the entire story with is my therapist. These people have all earned my trust over a period of several years [with the confiding starting near the time of the event]. In all cases, their reaction was shock, and then anger at the man who had been so cruel . . .. They have all been very caring and very supportive, helping my healing process when they could." (5) An example of present negative affect that produced a mean rating of 5.5 [by a 27 -year-old woman who had been raped by an acquaintance 10 years before): "I feel closer to resolution than I ever have 
before, though I know I have work yet to do on it. I feel less guilty, less like $I$ did something wrong. And I feel less rage . ..." (6) An example of present negative affect question that produced a mean rating of 9.5 [by a 42-year-old woman who had been assaulted by her mother repeatedly between 5 and 10]: "Shame and guilt that is deep and pervasive . . Sad, sometimes angry ... Most of my emotion has been diffused." (7) an example of negative impact on close relationships for a 30 year-old woman [after being raped by her father, stepfather, and uncles between 5 and 16] that produced a mean rating of 9.0: "I cannot have a close relationship with a man only as a friend because I hate to be touched sometimes. And they think I'm having sex with another man because I get this way. I try to explain about my past, but they say that's over. It shouldn't bother me anymore. If only it was them instead of me ...." In describing present negative affect, this woman went on to say, "Sometimes I cannot sleep because I have dreams of the past. I wake up crying in a cold sweat ... "

\section{DISCUSSION}

In this study, we were interested in the roles of account-making and confiding as part of the coping response to sexual assault. As was predicted, account-making was positively associated with success in coping and negatively related to present negative affect. Account-making was not, however, significantly related to participants' ratings of negative impact of the assault on their close relationships. This nonsignificant result may be due partially to the uniformly high negative impact ratings across all participants. For our participants the sexual nature of the assault, and the negative implications of this event for the development of trust in close others, may have offset any appreciable positive gain from account-making over time on close relationships.

As predicted, it was found that confiding early which was met with a helpful reaction led to more successful coping and less present negative affect than did confiding occurring early or late that was met with a nonhelpful reaction. Again, there was no significant association between confiding early and impact on close relationships. Our definition of early confiding as the expression of confidences to another about the assault occurring within the first 12 months after assault is somewhat arbitrary in terms of length. The first 12 months, however, may be critical to the development of trust by the survivor in a confidant and a belief in the possible efficacy of confiding. If productive confiding does not occur then (and especially in the case of a relatively young person), the person may decide 
that no one cares or that it is more punishing to confide than not to confide and try to insulate oneself against hurt from others' reactions. This state of affairs, then, may continue until much later in the person's life when further strength and motivation exist to again seek support through the confiding act. The present research provides only modest evidence about the value of confiding activity in dealing with sexual assault. It does, however, suggest that the process of confiding, which includes other's reactions to confiding attempts, the timing of the confiding attempt, and its relationship to other stress reduction steps, represents a valuable focus for future work.

The general finding in this study regarding the value of confiding about sexual assault that is met with a helpful reaction by others is consistent with evidence reported by Andrews and Brown (1988), who conducted research with a sample of women who had suffered spousal abuse in England. In their study, women who were abused by their husbands and who then experienced nonoptimal confiding encounters with others (e.g., rejection or obvious attempts to avoid discussion of the issue) showed various negative reactions such as characterological self-blame [i.e., blame of one's own personality or other personal qualities (JanoffBulman, 1979)].

An interesting issue for further investigation regarding the value of confiding is the extent to which on a universal basis confiding represents a helpful step for the survivor. It appears that confiding may be more commonly carried out (and may occur on an earlier basis) by survivors in Western than Eastern cultures (Ward, 1984). Ward's work (e.g., Ward, 1988) suggests that defense mechanisms often are used by sexual assault victims from Indian, Malay, and Chinese Cultures. No strong cross-cultural evidence about the relative value of confiding or account-making versus defense mechanisms such as denial and repression exists.

In accord with our prediction, it was found that on all outcome measures incest survivors had more difficulty in coping than did nonincest survivors. Incest survivors indicated that they experienced more negative impact on their close relationships, less success in coping, and greater present negative affect than did nonincest survivors. These data may be related to evidence reported by Roth and Lebowitz (1988) in a study of the psychological effects of sexual trauma. Their work emphasized a case-history approach for a small sample of individuals who were seeking treatment. Themes such as rage, helplessness, fear, self-blame, and isolation and alienation were common in the reports by Roth and Lebowitz's sample. As suggested by the excerpts from the accounts reported by participants in our study, such themes also were observed, and especially so in the reports of the incest group. We believe that a strong merit of open-ended measures 
(coupled as is possible with more structured measures) is that the scholar and clinician can gain a much clearer appreciation of the depth of impact for and continued suffering of survivors than is possible with only structured measures.

Overall, these data point to the importance of a set of conditions that may help survivors better deal with the aftermath of sexual assault. These conditions are the beginning and gradual refinement of account-making about the event and its meaning to the survivor and, if possible, early confiding in a close other(s) who provides a forum and helpful, caring support. We also found a positive effect on degree of account-making the earlier the confiding. This finding may suggest that early confiding helps the individual begin what may be a long process of developing an account that is felt to be both complete and helpful for the future.

This reasoning brings us to the final topic of the limitations of this study. There are many. The final sample is quite small, limited to the Midwestern United States, and it is unfortunate that only one male responded. We report on that male's response because we believe that other investigators may encounter this difficulty in securing male participants and need to go to great lengths to enlist a sample of male sexual assault survivors. We also do not have much evidence about the role of factors such as social attitudes and beliefs, religious up-bringing, substance abuse, or the objective nature of the social support network that existed for members of the sample which may have affected the survivors' responses. Nonetheless, the sample did provide considerable variation along the dimension of severity of assault and rated impacts of it in the respondents' lives.

Another limitation of the study is the self-selected nature of the sample. The people who participated in this study without great incentive may differ in a number of ways from people who decided not to participate. They may want to "tell their message" more strongly and be closer to resolution as compared to persons who elected not to participate. They may be (or have been) more involved in therapy and related accountmaking than are/were those who elected not to participate. They may even be better off psychologically than are persons who elected not to participate.

We also do not provide good cause-effect evidence about the roles of account-making and confiding in the coping process. Our evidence mainly is correlational and open to a variety of third-variable issues such as the possibility that certain personality factors account for health quite apart from the activities of account-making and confiding. Another intriguing question is, for those individuals who cope better, does private intensive account-making occur before public, productive confiding, or does such 
confiding lead to more intense account-making? Our study cannot establish a causal direction for these central processes.

In conclusion, this work suggests that people's accounts of pain and anguish and the confiding of aspects of such accounts to others who exhibit caring attitudes and behaviors may enhance recovery from sexual assault over time. We believe that these accounts have great potential to affect all of us in salutary ways and help us connect better with a world of suffering that always is right at our doorstep.

\section{ACKNOWLEDGMENTS}

The authors extend their deepest appreciation to the participants in this research who through their courage help us all understand better the trauma of sexual assault. We also thank Elizabeth Whitmore for help with the data analysis and three anonymous reviewers for their helpful comments.

\section{REFERENCES}

Andrews, B., and Brown, G. W. (1988). Social support, onset of depression and personality: An exploratory analysis. Social Psychiatry Psychiatric Epidemiol. 23: 99-108.

Becker, J. V., Skinner, L. J., Abel, G. G., and Treacy, E. C. (1982). Incidence and types of sexual dysfunctions in rape and incest victims. J. Sex. Marit. Ther. 1: 65-74.

Bruner, J. (1990). Acts of Meaning, Harvard University Press, Cambridge.

Cody, J. J., and McLaughlin, M. L. (1991). Interpersonal accounting. In Giles, H., and Robinson, P. (eds.), The Handbook of Language and Social Psychology, Wiley, London. In press.

Cohen, J. (1960). A coefficient of agreement for nominal scales. Ed. Psychological Measure. 20: $37-46$.

Coles, R. (1989). The Call of Stories, Houghton Mifflin, Boston.

Gergen, K. J., and Gergen, M. M. (1988). Narrative and the self as relationship. In Berkowitz, L. (ed.), Advances in Experimental Social Psychology, Vol. 2, Academic Press, Orlando, Fla., pp. 17-56.

Goffman, E. (1959). The Presentation of Self in Everyday Life, Doubleday-Anchor Books, Garden City, N.Y.

Harvey, J. H., Agostinelli, G., and Weber, A. L. (1989). Account-making and formation of expectations about close relationships. Rev. Personal. Social Psychol. 10: 39-62.

Harvey, J. H., Orbuch, T. L., and Weber, A. L. (1990). A social psychological model of account-making in response to severe stress. J. Lang. Social Psychol. 9: 191-207.

Harvey, J. H., Weber, A. L., and Orbuch, T. L. (1990). Interpersonal Accounts: A Social Psychological Perspective, Basil Blackwell, Oxford.

Harvey, J. H., Wells, G. L., and Alvarez, M.D. (1978). Attribution in the context of conflict and separation in close relationships. In Harvey, J. H., Ickes, W., and Kidd, R. F. (eds.), New Directions in Attribution Research, Vol. 2, Erlbaum, Hillsdale, N.J. pp. 235-259.

Horowitz, M. J. (1986). Stress Response Syndromes (second ed.), Jason Aronson, Northvale, N.J. 
Janoff-Bulman, R. (1979). Characterological versus behavioral self-blame: Inquiries into depression and rape. J. Personal. Social Psychol. 37: 1798-1809.

Koss, M. P. (1985). The hidden rape victim: Personality, attitudinal, and situational characteristics. Psychol. Wom. Quart. 12: 1-24.

Koss, M. P. (1990). Violence against women. Am. Psychologist, 45: 374-380.

Lyman, S. M., and Scott, M. B. (1970). A Sociology of the Absurd, Appleton-Century-Crofts, New York.

Miller, W. R., Williams, A. M., and Bernstein, M. H. (1982). The effects of rape on marital and sexual adjustment. Am. J. Fam. Ther. 10: 51-58.

Pennebaker, J. W. (1989). Confession, inhibition, and disease. In Berkowitz, L. (ed.), Advances in Experimental Social Psychology, Vol. 22, Academic Press, Orlando, Fla., pp. 211-244.

Pennebaker, J. W. (1985). Traumatic experience and psychosomatic disease: Exploring the roles of behavioral inhibition, obsession, and confiding. Canad. Psychol. 26: 82-95.

Quina, K., and Carlson, N. L. (1989). Rape, Incest, and Sexual Harassment: A Guide for Helping Survivors, Praeger, New York.

Roth, S., and Lebowitz, L. (1988). The experience of sexual trauma.J. Traum. Stress, 1: 79-107.

Silver, R., Boon, C., and Stones, M. (1983). Searching for meaning in misfortune: Making sense of incest. J. Social Issues, 39: 81-102.

Taylor, S. E., Wood, J. V., and Lichtman, R. R. (1983). It could be worse: Selective evaluation as a response to victimization. $J$. Social Issues, 39: 19-40.

Ward, C. (1988). Stress, coping and adjustment in victims of sexual assault: The role of psychological defense mechanisms. Counsel. Psychol. Quart. 1: 165-178.

Ward, C. (1984). The trauma of sexual assault: Psychological stress and coping in adolescent victims. In Leong, Y. C., Chiam, H., and Chew, L. (eds.), Preparation for Adullhood: Proceedings of the Third Asian Workshop on Child and Adolescent Development, University of Malaya Press, Kuala Lumpur.

Weber, A. L., Harvey, J. H., and Stanley, M. A. (1987). The nature and motivations of accounts for failed relationships. In Burnett, R., McGhee, P., and Clarke, D. C. (eds.), Accounting for Relationships, London, Methuen, pp. 114-133.

Weiss, R. S. (1975). Marital Separation, Basic Books, New York. 